\title{
Book of man
}

\section{History of Physical Anthropology: \\ An Encyclopedia}

edited by Frank Spencer

Garland: 1997. 2 Volumes. Pp. 1,195. \$175

\section{Clark Howell}

This book is the first comprehensive encyclopaedic treatment of the discipline of physical anthropology - the natural history of humankind. It provides brief biographical sketches of some 302 figures, mostly historical; summaries of development, both disciplinary and institutional; and entries on essential areas of scientific enquiry and theory. There are 169 contributors, from 34 countries, and the masterful editorial hand of Frank Spencer is manifest throughout the consistently readable text. He contributes many biographical profiles and several topical entries.

There is an extensive index of names and a thoroughly cross-referenced subject index. Much of the history of the field is exemplified in the abundant biographical profiles. In the 1800 s, it is represented by many physicians, anatomists, zoologists, naturalists, palaeontologists and geologists. At that time, some form of 'normal' science was practised, but the influence of Darwinism, even if acknowledged, was scarcely noticeable. Only in the past 50 years did the field become professionalized.

Some recent figures who were particularly important to the profession lack biographical treatment: W. C. Boyd, A. A. Dahlberg, A. E. Mourant, H. J. Muller, S. Wright, A. C.

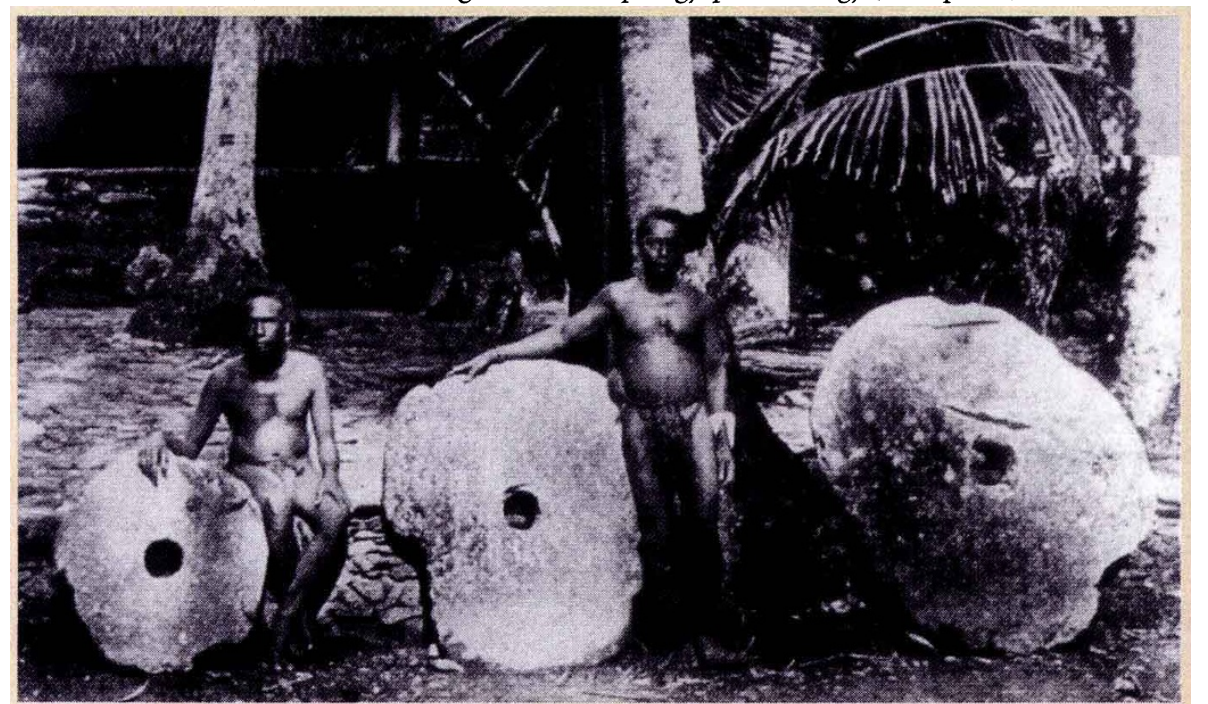

\section{Hard currency}

Nineteenth-century Yap islanders made big money. But there was no danger of these coins burning a hole in the pocket as they took the form of stones up to 4 metres across. The stones were cut from limestone quarries on islands some 400 miles away and carried by sea to Yap, in what is now Micronesia. From Money:
Wilson and J. S. Huxley (whose grandfather does appear). Thirty-five entries summarize the emergence, development and modern condition of the field - largely since the 1950s - in countries of the Americas (10), Europe (16), Africa (1), Middle East (2), Asia (4) and Antipodes (2). Further insights into historical aspects are found in entries on scientific academies, professional societies and associations, laboratories, museums, universities, journals/serials and influential foundations and government bodies.

No single entry reflects the nature, scope and theory of physical anthropology. The discipline is not about chain of being, catastrophism, creationism, eugenics, phrenology, polygenism, Rassenhygiene, Rassenkunde, all of which have their own entries. The field does acknowledge and employ concepts, approaches and methodologies, including biogeography, (neo-) Darwinism (not Lamarckism), evolutionary theory, (Mendelian) genetics (and genetic drift), punctuated equilibrium, paleoanthropological theory, race, systematics, taphonomy and uniformitarianism. But there should have been entries as well on cladistics, ethnic groups, extinction, life history, phylogeny, populations, species and taxonomy.

Most concerns of the discipline encompass adaptation, anthropometry (as technique), bipedalism (within locomotion), body composition, comparative neuroanatomy, demography (and associated population biology and genetics), dental anthropology, dermatoglyphics, growth (and aging), health and disease, molecular anthropology, paleoanthropology, primatology (all aspects), skeletalbiol-

A History, edited by Jonathan Williams (British Museum Press, £25, St Martins Press $\$ 29.95)$. The book was written by curators at the British Museum in London and was published to coincide with the opening of a new gallery at the museum exploring the history of money. ogy (and paleopathology). The encyclopaedia also deals with the interface and interactions between biology, behaviour and culture (as in the hunting hypothesis of human origins).

Primate studies have become a central focus in a field long dominated by concerns with mankind. Since Edward Tyson in the seventeenth century, various individuals have contributed knowledge of primate biology, diversity and structure. Field studies were minimal and pioneering until some 40 years ago. A half-dozen entries deal with the history and status of prosimian, simian and ape field studies in general and on several continents. Similarly, studies of the primate fossil record have expanded vastly in recent decades, and one of the longest and best entries is that on paleoprimatology.

Palaeoanthropology, reflecting human evolutionary studies from biological and cultural/behavioural perspectives, is among the most visible and familiar of the field's foci. Strangely, it lacks an inclusive entry (other than an historical treatment, paleoanthropology theory). It principally encompasses Java, Asian and Australian (paleoanthropology), and an expansive and topical piece on modern human origins. The relevant fossil record is treated idiosyncratically with entries on Australopithecines, Homo habilis, Homo erectus and Neanderthals. Homo sapiens is not to be found, although more than 20 index citations under Homo are to species nomina, among them sapiens, including the informal (and unacceptable) 'archaic' and 'early modern' designations. The lack of exposition of hominin syste-matics is a serious omission. Many, but by no means exhaustive, entries on important fossil-bearing formations/ localities - from Afar to Olduvai Gorge and Omo to Zhoukoudian - provide additional information to flesh out the treatment of hominid (hominin) evolution and phylogeny. Lacking are entries on Atapuerca, Dmanisi and Kanapoi, among others. Fuller, more structured treatments are to be found in The Cambridge Encyclopaedia of Human Evolution edited by S. Jones, R. Martin and D. Pilbeam (Cambridge University Press, 1992; for a review see Nature 361,$314 ; 1993$ ) and in Encyclopaedia of Human Evolution and Prehistory edited by I. Tattersall, E. Delson and J. van Couvering (Garland, 1988; see Nature 335, 598; 1988).

History of Physical Anthropology is an important addition to the reference literature. It will inform nonbiological practitioners about the study of humankind as well as those in the many increasingly fissioned specialities of the life sciences.

Clark Howell is in the Laboratory for

Human Evolutionary Studies,

Museum of Vertebrate Zoology,

University of California,

Berkeley 94720, California, USA. 